\title{
Glycemic Index of (Zummita) A Commonly Barley Based Consumed Traditional Libyan Food
}

\author{
Mohamed Ahmida ${ }^{1}$, Akram Elshebli ${ }^{1}$, Ahmed Elzigl ${ }^{1}$, Elmutazbellah Siddek $^{1}$ \\ ${ }^{1}$ Department of Nutrition, Faculty of Public Health, Benghazi University, 21861 Benghazi, Libya
}

\section{A R T I C L E I N F O}

Article history:

Received 20 November 2014

Accepted 09 February 2015

Available online, ISSN: 2148-127X

Keywords:

Zummita

Glycemic index

Type 2 diabetes

Benghazi

Libya

$\overline{{ }^{*} \text { Corresponding Author: }}$

\section{A B S T R A C T}

In Libya especially in Benghazi, Zummita is a traditional Libyan food consisting of $85 \%$ whole barley flour and is commonly consumed as a breakfast meal, and. Due to an increase in Type 2 diabetes and a lack of information on the effects of Zummita consumption on glycemic response, this study was performed to determine the glycemic index (GI) of Zummita. Fasted healthy subjects (6 males and 6 females) volunteered to consume either glucose or Zummita. The blood glucose concentrations were analyzed using capillary blood samples immediately before, 30, 60, 90 and 120 min after glucose or Zummita consumption. The GI value of Zummita was calculated by expressing the incremental area under the blood glucose response curve (IAUC) value for Zummita as a percentage of each subject's average IAUC value for the glucose. The GI value of Zummita was found as $46.90 \pm 7.56$. This result indicates that Zummita should be classified as low GI food. More importantly, our result provides the GI value of a Libyan traditional food which was not determined previously. This valuable information will be significant for management and the prevention of diabetes mellitus in Libya and other countries having similar food tradition.

\section{Introduction}

Benghazi is similar to other affluent cities where diabetes is the major health problem. Reports show that the prevalence of diabetes in Benghazi is $14.1 \%$ (Roaeid and Kablan, 2007). A popular concept introduced by Jenkins and his colleagues in 1981 known as the glycemic index (GI) has been of potential benefit. A ranking of foods is based on their actual postprandial plasma glucose response compared with that of a reference food which is either glucose or white bread The GI is calculated by measuring the incremental area under the plasma glucose curve following an ingestion of a test food providing $50 \mathrm{~g}$ of carbohydrate (Jenkins et al., 1981). This incremental area is then compared with the area under the plasma glucose curve following an equal carbohydrate intake from the reference food taken by the same test subject. In the calculation of GI value of the food of interest, area under the plasma glucose curve following the consumption of reference food is set to be 100 . Consuming high glycemic indices foods have been linked with a number of chronic diseases, such as diabetes (Salmerón et al., 1997a and Salmerón et al., 1997b), metabolic syndrome (McKeown et al., 2004), cardiovascular diseases (Liu et al., 2000) and even some types of cancers (Augustin et al., 2004). However, it has been demonstrated that low GI regimens increase body fat loss in overweight and obese adolescents (McMillan-Price et al., 2006). Moreover, Low GI diets have been found to reduce risk of coronary heart disease (CHD) (Barclay et al., 2008) and have a small but clinically useful effect on medium-term glycemic control in patients with diabetes (Brand-Miller et al., 2003).

Some foods on the world market already have their GI ratings on the nutrition information panel. Terms such as complex carbohydrates and sugars, which commonly appear on food labels, are now recognized as having little nutritional or physiological significance. The World Health Organization (WHO) and Food and Agriculture Organization (FAO) recommend these terms be replaced with the total carbohydrate contents of the food and its GI value. The glycemic index values for many local and traditional Libyan foods have not been defined yet. Therefore, any effort for the determination and practical use of GI value of Libyan traditional foods may support establishing optimum dietary recommendations and good eating habits. Zummita, a traditional Libyan food, is a mixture made up of $85 \%$ whole barley flour along with the rest made up from cumin, coriander, fennel, and caraway. These are dry roasted in an empty frying pan until golden brown, then ground into powder and sieved. The powder is finally placed in clay jars for one year that give it a specific aroma. Zummita was prepared easily by mixing with water until it become firm and doughy. It is 
consumed by dipping a small bit in olive oil. The purpose of this study was to determine GI value of Libyan traditional food, Zummita which may act as the basis for the development of a GI database for Libyan traditional foods.

\section{Materials and Methods}

\section{Tested foods}

Two foods with known contents of nutrient were tested: (1) Pure glucose (Merck, Germany), one serving contained $50 \mathrm{~g}$ glucose that was dissolved in $250 \mathrm{ml}$ tap water before drinking, (2) Zummita, it was commercially produced in Libya as traditional food and obtained from local market of Benghazi city. Zummita was analyzed in the laboratory of the Department of Nutrition, Faculty of Public Health, Benghazi University for nutrient composition using standard AOAC methods (AOAC, 1983). Moisture was determined by oven drying at $105^{\circ} \mathrm{C}$ for $20 \mathrm{~h}$. the protein content was estimated (nitrogen $\mathrm{x}$ 6.25) from quantitative analysis of nitrogen by using Kjeldahl method. The fat was measured gravimetrically by extraction in diethyl ether and petroleum ether. An available carbohydrate was calculated by difference. These analysis were carried out in triplicate.

Zummita; composition: carbohydrates, $77.35 \%$; protein, $6.78 \%$; fat, $2.50 \%$; energy, $359.02 \mathrm{kcal} / 100 \mathrm{~g}$. $64.64 \mathrm{~g}$ of Zummita was served to the subjects that found to be equal to $50 \mathrm{~g}$ of available carbohydrates in Zummita calculated from the results of the proximate analysis.

\section{Participants}

Twelve healthy nonsmoking adults (6 males and 6 females, mean \pm SE: age, $22.3 \pm 1.4$ years; BMI, $21.6 \pm$ $0.9 \mathrm{~kg} / \mathrm{m}^{2}$ ) volunteered to participate in the study. All subjects reported no history of diabetes, they were without drug therapy and all female subjects were non pregnant and non-lactating. Ethical approval for the present study was obtained from the department of Nutrition, Public Health Science, the University of Benghazi. Before the beginning of the study, subjects were given full details about its nature and purpose and the opportunity to ask questions. The study was performed over a period of one month and all subjects were aware of the possibility of withdrawing from the study at any time.

\section{Procedures}

The GI value of Zummita was determined by using the Food and Agriculture Organization (FAO) recommended methods (FAO/WHO, 1998). All subjects were required to avoid doing vigorous physical activities $24 \mathrm{~h}$ before test. They were required not to consume large meals and but instead have a balanced diet on the day before the test. After 10-14 h overnight fast, the subjects were required to present to the Nutrition laboratory between 8 am and $10 \mathrm{am}$. On arrival, the subjects rested for around $15 \mathrm{~min}$ and the baseline finger-prick capillary samples were collected. Then the subjects consumed either reference (50 g glucose) or Zummita containing 50 $\mathrm{g}$ of available carbohydrate. Each subject was given $50 \mathrm{~g}$ glucose or Zummita three times. The intervals between two tests were at least two days. All food were required to be consumed within $10 \mathrm{~min}$. Further blood samples were collected at 30, 60, 90, and 120 min after starting to eat. All the blood samples were analyzed with Accu-chek glucose analyzer (Accu-chek Advantage System, Roche Diagnostics Limited, Germany).

\section{Glycemic index determination}

Blood glucose response curve was constructed from the average blood glucose concentration obtained pre- and post-Zummita ingestion as a function of time. The incremental area under the curve (IAUC) was calculated for each tested food (glucose or Zummita) in each subject, as the sum of the surface triangles and trapezoids between the blood glucose curve and the horizontal baseline running in parallel to the time axis from the beginning of the curve to the point at $120 \mathrm{~min}$. The IAUC for $50 \mathrm{~g}$ of pure glucose was obtained in a similar way (Camille et al., 2014).

The GI for Zummita was calculated using the formula:

$$
\mathrm{GI}=\left(\mathrm{IAUC} / \mathrm{IAUC}_{\mathrm{g}}\right) \times 100 \% \text {. }
$$

The average of the three measures for each subject was taken as the GI for Zummita for the subject. The GI for Zummita was finally calculated as the mean of the average of the GIs in twelve subjects in the group.

\section{Statistical analysis}

Analysis of data was performed using SPSS statistical software package. Results are expressed as means with their standard errors. Statistical analysis of glycemic indices were performed using Paired $t$-test. $\mathrm{P}<0.05$ was considered statistically significant.

\section{Results and Discussion}

The mean blood glucose responses up to $120 \mathrm{~min}$ following ingestion of Zummita and glucose are shown in Figure 1. Fasting blood glucose levels did not differ before the treatments. The blood glucose level for Zummita was significantly lower at 30, 60 and $90 \mathrm{~min}$ than that for the glucose $(\mathrm{P}<0.05)$. Areas under the glucose concentration-time curves for the participants in the study given glucose and Zummita were $193.62 \pm$ 32.48 and $90.86 \pm 13.53 \mathrm{mg} . \mathrm{min} / \mathrm{dL}$, respectively. When the glycemic index of the glucose reference treatment was set to 100 , the corresponding glycemic index for Zummita was $46.57 \pm 6.15 \%$. This value indicates that Zummita should be classified as low GI food (Table 1).

Table 1 Area under the curve (AUC), glycemic index (GI) and glycemic index classification of Zummita.

\begin{tabular}{l|c}
\hline & Mean \pm s.e.m \\
\hline AUC-Glucose (mg.min /dL) & $193.62 \pm 32.48$ \\
AUC-Zummita (mg.min /dL) & $90.86 \pm 13.53^{*}$ \\
GI $(\%)$ & $46.57 \pm 6.15$ \\
GI classification & Low \\
\hline
\end{tabular}

$\mathrm{n}=12$ volunteers ( 3 tests for Glucose and 3 tests for Zummita for every volunteer, the intervals between two tests were at least two days); states that AUC of Zummita is significantly different $(\mathrm{P}<0.05)$ than AUC of glucose., s.e.m.:- Standard Error of the Mean 


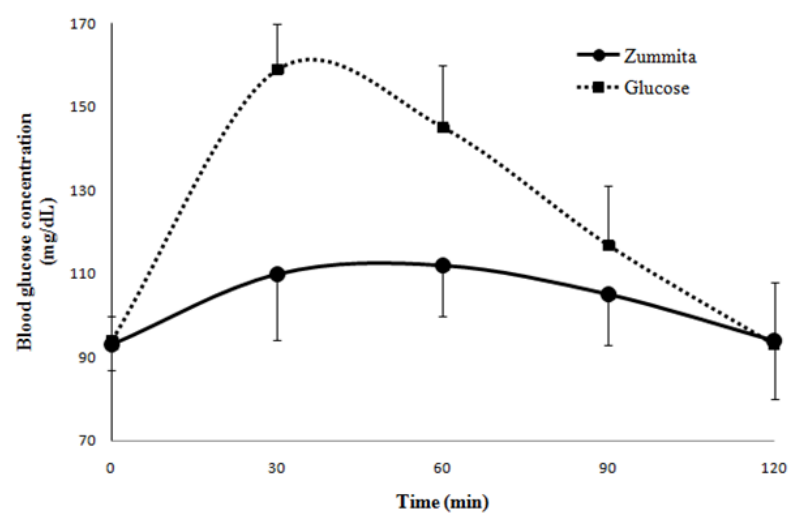

Figure 1. Glycemic response for 30, 60, 90, and $120 \mathrm{~min}$ after consumption of glucose and Zummita by 12 volunteers ( 3 tests for glucose and 3 tests for Zummita for every volunteer, the intervals between two tests were at least two days). Significant difference $(\mathrm{P}<0.05)$ between points at the same time intervals is marked with (*) on Zummita curve.

To our knowledge, this is the first report on the glycemic index of Zummita, a commonly barley based Libyan traditional food. The glycemic index provides a way to classify carbohydrate-rich foods according to the magnitude of the glycemic response following intake (Jenkins et al., 1981). Using a more physiologically based classification of foods according to their glycemic indices, dietetic strategies have been developed for human athletes and non-insulin-dependent diabetics. In human athletes, ingestion of high- glycemic index foods after exercise results in greater synthesis of muscle glycogen (Burke et al., 1993) compared with the ingestion of equal amounts of carbohydrates as low- glycemic index foods. Similarly, low-glycemic index diets have been shown to improve glycemic control in non-insulin-dependent diabetics and to reduce serum lipids in hyperlipidemic subjects (Jenkins et al., 2002). There is sufficient evidence of durable benefits to recommend using these diets as a primary strategy in meal planning to decrease risk of developing type 2 diabetes, cardiovascular disease and certain cancers (Venn and Green, 2007). According to the official classification of glycemic index, foods may be divided into three groups: foods with low glycemic index $(\leq$ $55 \%$ ), foods with medium glycemic index (56-69\%) and foods with high glycemic index $(\geq 70 \%)$ (Venn and Green, 2007; Atkinson et al., 2008; Chlup et al., 2004).

The current study examined the postprandial glycemic response to Zummita. Our results showed that the glycemic index of Zummita was $46.90 \pm 7.56 \%$. Therefore Zummita should be classified as a low glycemic index diet. The magnitude of the glycemic response to ingestion of a carbohydrate-rich meal reflects the rate of digestion and absorption. In the case of barley commonly used in preparation of Zummita, starch makes up most of the carbohydrate; therefore, starch digestibility depends on its prior physical and thermal treatments and biochemical composition. Indeed, GI of mixed meals is reduced by co-ingestion of protein, fiber or fat. The presence of large amounts of protein or fat may significantly reduce the glycemic response by increasing insulin secretion and slowing gastric emptying (Lok et al., 2010; Camille et al., 2014). The lower consumption of grains that are rich sources of dietary fiber may be associated with the increasing prevalence of chronic diseases like diabetes and coronary heart disease (Parastouei et al., 2011). Barley which is the main constituent of Zummita is a great source of soluble fibers especially viscous fibers which have been shown to reduce postprandial glucose (Würsch and Pi-Sunyer, 1997; Wolever, 2000; Jenkins et al., 2000). Kalpana et al. (1991) showed that Barley also has some unknown insulinotropic factors which is specially effective in noninsulin dependent diabetes mellitus. Among the various grains, barley is highly viscous in character. Indeed, the viscosity of barley is mainly derived from the $\beta$-glucan content (Mathlouthi et al., 2002). $\beta$-glucan has been reported to suppress postprandial glucose levels (Tappy et al., 1996). A possible mechanism to explain these results might involve the reduction of gastric emptying and the increases gastrointestinal transit time. Soluble fibers also slow the rate of starch digestion by pancreatic amylases in vitro, probably by delaying the interaction of the enzyme with the substrate. These factors cause delayed and reduced carbohydrate absorption from the gut (Battilana et al., 2001). In addition, the degree of viscosity of the fiber is positively related to the extent of flattening of the postprandial glucose response (Jenkins et al., 2002).

\section{Conclusion}

The present study has provided reliable value of glycemic index for a commonly barley based consumed traditional Libyan food. Zummita has a low-glycemic index value. This datum has not been previously tested in Libya. Knowledge of glycemic index value of Zummita may serve in the development of much better dietary advice for the individuals with diabetes and obesity. This information will also be useful for the researchers interested in the application of glycemic index in dietary surveys to study diet-disease relationships, and in the planning of dietary intervention studies.

\section{References}

AOAC. 1983. Official Methods of Analysis $13^{\text {th }}$ Edition, Association of Official Analytical Chemists. Washington DC. pp. 755-800.

Atkinson FS, Foster-Powell K, Brand-Miller JC. 2008. International tables of glycemic index and glycemic load values: 2008 . Diabetes Care, 31:2281-2283.

Augustin LS, Gallus S, Negri E, La Vecchia C. 2004. Glycemic index, glycemic load and risk of gastric cancer. Ann Oncol., 15:581-584.

Barclay AW, Petocz P, McMillan-Price J, Flood VM, Prvan T, Mitchell P, Brand-Miller JC. 2008. Glycemic index, glycemic load, and chronic disease risk--a meta-analysis of observational studies. Am J Clin Nutr., 87:627-637.

Battilana P, Ornstein K, Minehira K, Schwarz JM, Acheson K, Schneiter P, Burri J, Jéquier E, Tappy L. 2001. Mechanisms of action of beta-glucan in postprandial glucose metabolism in healthy men. Eur. J. Clin. Nutr., 55:327-333.

Brand-Miller J, Hayne S, Petocz P, Colagiuri S. 2003. Lowglycemic index diets in the management of diabetes: a metaanalysis of randomized controlled trials. Diabetes Care, 26:2261-2267. 
Burke LM, Collier GR, Hargreaves M. 1993. Muscle glycogen storage after prolonged exercise: Effect of the glycemic index of carbohydrate feedings. J. Appl. Physiol., 75:1019-1023.

Camille AK, Nestor KK, Aïssatou C, Denis YN, Georges GT, Lokrou A, Georges NA. 2014. Glycemic Index and Glycemic Load of Selected Staples Based on Rice, Yam and Cassava Commonly Consumed in Côte d'Ivoire. Food and Nutrition Sciences, 5:308-315.

Chlup R, Bartek J, Reznickova M, Zapletalova J, Doubravova B, Chlupova L, Seckar P, Dvorackova S, Simanek V. 2004. Determination of the glycaemic index of selected foods (white bread and cereal bars) in healthy persons. Biomed Pap Med Fac Univ Palacky Olomouc Czech Republic. 148:17-25.

FAO/WHO. 1998. Carbohydrates in human nutrition. Report of a Joint FAO/WHO Expert Consultation. FAO Food Nutr Pap. 66:1-140.

Jenkins DJ, Wolever TM, Taylor RH, Barker H, Fielden H, Baldwin JM, Bowling AC, Newman HC, Jenkins AL, Goff DV. 1981 Glycemic index of foods: a physiological basis for carbohydrate exchange. Am J Clin Nutr., 34:362-366.

Jenkins DJ, Axelsen M, Kendall CW, Augustin LS, Vuksan V, Smith U. 2000. Dietary fibre, lente carbohydrates and the insulin-resistant diseases. Br. J. Nutr., 83:S157-S163.

Jenkins DJ, Kendall CW, Augustin LS, Franceschi S, Hamidi M, Marchie A, Jenkins AL, Axelsen M. 2002. Glycemic index: Overview of implications in health and disease. Am. J. Clin. Nutr., 76:266S-273S.

Kalpana S, Narain JP, Purl P, Gupta A, Bijlani RL, Mahapatra SC, Karmarkar MG. 1991. Glycaemic response to Maize, Bajra and Barley. Indian J Physiol Pharmacol., 35:249-254.

Liu S, Willett WC, Stampfer MJ, Hu FB, Franz M, Sampson L, Hennekens CH, Manson JE. 2000. A prospective study of dietary glycemic load, carbohydrate intake, and risk of coronary heart disease in US women. Am J Clin Nutr., 71:1455-1461.

Lok KY, Chan R, Chan D, Li L, Leung G, Woo J, Lightowler HJ, Henry CJK. 2010. Glycaemic Index and Glycaemic Load Values of a Selection of Popular Foods Consumed in Hong Kong. Br. J.Nutr., 103:556-560.
Mathlouthi N, Saulnier L, Quemener B, Larbier M. 2002. Xylanase, beta-glucanase, and other side enzymatic activities have greater effects on the viscosity of several feedstuffs than xylanase and beta-glucanase used alone or in combination. J. Agric. Food Chem., 50:5121-5127.

McKeown NM, Meigs JB, Liu S, Saltzman E, Wilson PW, Jacques PF. 2004. Carbohydrate nutrition, insulin resistance, and the prevalence of the metabolic syndrome in the Framingham Offspring Cohort. Diabetes Care, 27:538-546.

McMillan-Price J, Petocz P, Atkinson F, O'neill K, Samman S, Steinbeck K, Caterson I, Brand-Miller J. 2006. Comparison of 4 diets of varying glycemic load on weight loss and cardiovascular risk reduction in overweight and obese young adults: a randomized controlled trial. Arch Intern Med., 166:1466-1475.

Parastouei K, Shahaboddin ME, Motalebi M, Mirhashemi SM, Faraji AM, Seyyedi F. 2011. Glycemic index of Iranian rice. Scientific Research and Essays, 6:5302-5307.

Roaeid RB, Kablan AA. 2007. Profile of diabetes health care at Benghazi Diabetes Centre, Libyan Arab Jamahiriya. Eastern Mediterranean health journal, 13:168-176.

Salmerón J, Manson JE, Stampfer MJ, Colditz GA, Wing AL, Willett WC. 1997a. Dietary fiber, glycemic load, and risk of non-insulin-dependent diabetes mellitus in women. JAMA, 277:472-477.

Salmerón J, Ascherio A, Rimm EB, Colditz GA, Spiegelman D, Jenkins DJ, Stampfer MJ, Wing AL, Willett WC. 1997b. Dietary fiber, glycemic load, and risk of NIDDM in men. Diabetes Care, 20:545-550.

Tappy L, Gügolz E, Würsch P.1996. Effects of breakfast cereals containing various amounts of beta-glucan fibers on plasma glucose and insulin responses in NIDDM subjects. Diabetes Care, 19:831-834.

Venn BJ, Green TJ. 2007. Glycemic index and glycemic load: measurement issues and their effect on diet-disease relationships. Eur J Clin Nutr., 61:122-131.

Wolever TM. 2000. Dietary carbohydrates and insulin action in humans. Br. J. Nutr., 83:S97-S102.

Würsch P, Pi-Sunyer FX. 1997. The role of viscous soluble fiber in the metabolic control of diabetes. A review with special emphasis on cereals rich in beta-glucan. Diabetes Care, 20:1774-1780. 